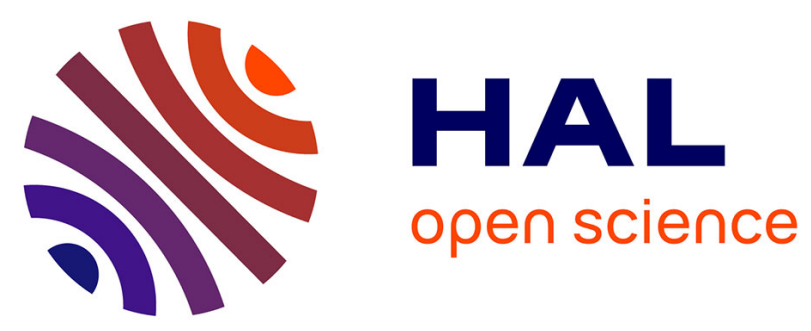

\title{
State of the art and current limits of musculo-skeletal models for clinical applications
}

Laurence Cheze, Florent Moissenet, Raphaël Dumas

\section{To cite this version:}

Laurence Cheze, Florent Moissenet, Raphaël Dumas. State of the art and current limits of musculoskeletal models for clinical applications. Movement \& Sport Sciences - Science \& Motricité, 2015, 90, pp. 7-17. 10.1051/sm/2012026. hal-01303890v2

\section{HAL Id: hal-01303890 \\ https://hal.science/hal-01303890v2}

Submitted on 22 Apr 2016

HAL is a multi-disciplinary open access archive for the deposit and dissemination of scientific research documents, whether they are published or not. The documents may come from teaching and research institutions in France or abroad, or from public or private research centers.
L'archive ouverte pluridisciplinaire HAL, est destinée au dépôt et à la diffusion de documents scientifiques de niveau recherche, publiés ou non, émanant des établissements d'enseignement et de recherche français ou étrangers, des laboratoires publics ou privés. 


\title{
STATE OF THE ART AND CURRENT LIMITS OF MUSCULO-SKELETAL MODELS FOR CLINICAL APPLICATIONS
}

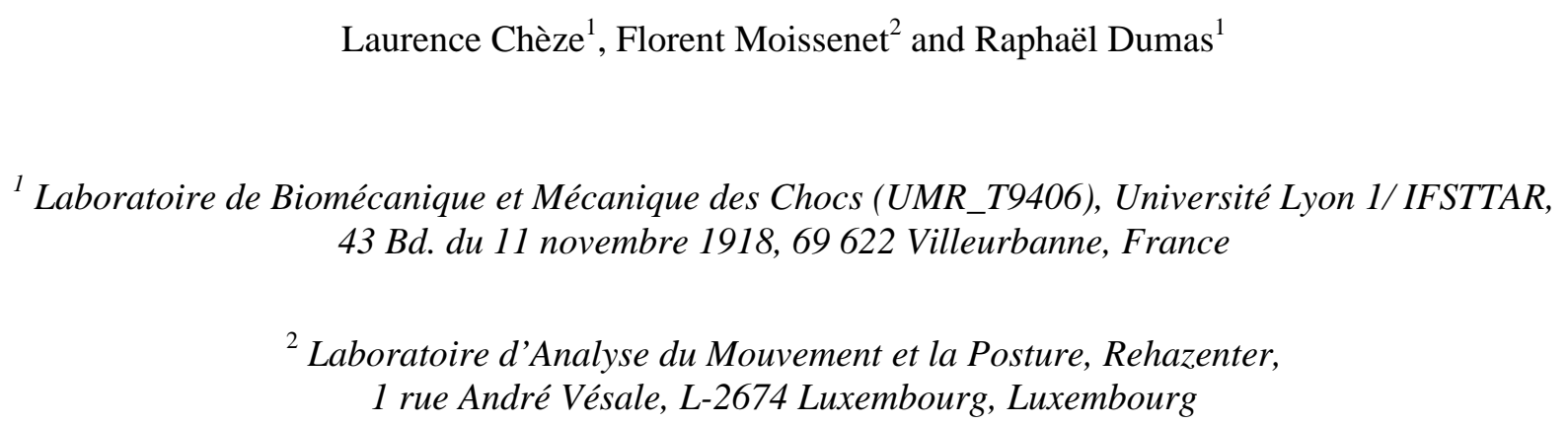

${ }^{1}$ Laboratoire de Biomécanique et Mécanique des Chocs (UMR_T9406), Université Lyon 1/ IFSTTAR, 43 Bd. du 11 novembre 1918, 69622 Villeurbanne, France

${ }^{2}$ Laboratoire d'Analyse du Mouvement et la Posture, Rehazenter, 1 rue André Vésale, L-2674 Luxembourg, Luxembourg

\begin{abstract}
The prediction of musculo-tendon forces developed during daily living tasks is essential to assess movement control and joint contact forces, and then provide insight to improve diagnosis and treatment follow-up of neurological and orthopedic disorders. Direct measurement of the musculo-tendon forces is hardly possible and the redundancy inherent in the musculo-skeletal system yields not enough equilibrium equations to compute these forces. Different methods have been proposed to overcome this problem, requiring numerous input parameters, most of them difficult or impossible to adjust to a specific subject. These methods will be exposed and their limits pointed out. Anyway, further development is needed in order that the model-based prediction of musculo-tendon forces can be used for clinical purposes.
\end{abstract}

\section{Résumé}

La prédiction des forces musculo-tendineuses développées au cours des tâches de la vie courante est essentielle pour accéder au contrôle du mouvement et aux actions de contact articulaires, et permet d'améliorer le diagnostic et le suivi du traitement des désordres neurologiques et orthopédiques. La mesure directe des forces musculo-tendineuses est difficilement réalisable et la redondance inhérente au système musculo-squelettique induit un nombre d'équations d'équilibre insuffisant pour calculer ces forces. Plusieurs méthodes ont 
1 été proposées pour résoudre ce problème, mais elles requièrent de nombreux paramètres

2 d'entrée, pour la plupart difficiles ou impossibles à ajuster à un sujet spécifique. Ces

3 méthodes vont être décrites et leurs limites soulignées. Quoi qu’il en soit, de nouveaux

4 développements sont nécessaires avant que les forces musculo-tendineuses prédites par les

5 modèles puissent être utilisées dans le cadre d'applications cliniques.

6

7 Current title : musculo-skeletal models

8

9 Key-words : musculo-tendon forces, joint contact forces, EMG-driven, forward dynamics, 10 static optimization 


\section{Introduction}

Musculo-skeletal and neurological pathologies are becoming a major problem of public health. To achieve a better understanding and treatment of these disorders, clinical studies make more and more use of biomechanical modelling. The models allow a better description of movement by quantifying its kinematical (i.e., joint angles, velocities and accelerations) and dynamical (i.e., motor joint moments) properties (Cappozzo, Catani, Croce, \& Leardini, 1995). Nevertheless, the motor joint moments represent the resultant action of all muscles spanning the joint and the muscular redundancy - about 630 skeletal muscles for 244 degrees of freedom (DoF) in the whole body (Prilutsky \& Zatsiorsky, 2002) - requires the use of specific methods to predict the individual musculo-tendon forces, and then deduce the joint reaction forces (i.e., contact forces and ligament forces). These results cannot be directly validated as in vivo measurement of musculo-tendon forces is limited to the use of miniinvasive devices on superficial tendons (Bey \& Derwin, 2012; Fleming \& Beynnon, 2004; Komi, 1990). Similarly, the measurement of the joint contact forces requires the use of instrumented prostheses and is therefore limited to pathologic patients (Brand et al., 1994; Fregly, Besier, et al., 2012; Lu, O'Connor, Taylor, \& Walker, 1998; Stansfield et al., 2003). Consequently, the accurate prediction of joint contact forces, critical for clinical applications such as preventing degenerative disorders and designing replacement prostheses (Besier, Gold, Beaupre, \& Delp, 2005; Pedersen, Brand, \& Davy, 1997; Pustoc'h, Bonnefoy, LabesseJied, Lavigne, \& Cheze, 2011; Steele, Demers, Schwartz, \& Delp, 2012), is not yet fully achieved.

The aim of this paper is to establish a state of the art of the main methods developed to predict both individual musculo-tendon forces and joint reaction forces, which will be presented and critically evaluated in order to conclude about their possible use in a clinical context. 


\section{Musculo-skeletal models}

3

4

$a_{j}=\left(e^{A \cdot u_{j}}-1\right) /\left(e^{A}-1\right)$

\subsection{Contraction dynamics model}

Since it is not possible to activate or desactivate a muscle instantaneously, a delay exists between the muscle excitation $u_{j}$ and the muscle activation $a_{j}$. This delay is due mainly to the time needed to pump out the calcium stored in the sarcoplasmic reticulum (Ebashi, 1972). Lloyd and Besier proposed the following formulation to characterize this nonlinear relationship (Lloyd \& Besier, 2003):

where $A$ is a nonlinear shape factor, constrained to $-3<A<0$.

(Equation 1)

\subsection{Musculo-tendon dynamics model}

Using a Hill-type model (i.e., a muscle fiber in series with a tendon (Zajac, 1989)), the musculo-tendon force $f_{j}$ can be deduced from the muscle activation $a_{j}$. The musculo-tendon force is directly linked to the force of both structures with the following equation (Buchanan, Lloyd, Manal, \& Besier, 2004; Hoy, Zajac, \& Gordon, 1990; Lloyd \& Besier, 2003; Shao, 
1 where $f_{j}^{T}$ and $f_{j}^{M}$ are respectively the tendon force and muscle fiber force and $\varphi_{j}$ is the

2 pennation angle between these structures.

3 Consequently, compute the musculo-tendon force amounts to compute the muscle fiber force

4 that is typically computed as follow (Buchanan et al., 2004; Lloyd \& Besier, 2003; Shao et al.,

5 2009; Winter \& Challis, 2010):

$6 \quad f_{j}^{M}=f_{j}^{M_{0}} \cdot\left(f_{j}^{M_{a}}\left(l_{j}^{M}\right) \cdot f_{j}^{M_{v}}\left(v_{j}^{M}\right) \cdot a_{j}+f_{j}^{M_{p}}\left(l_{j}^{M}\right)\right)$

(Equation 3)

7 where $f_{j}^{M_{0}}$ is the maximum isometric muscle force (i.e. the muscle force developed for the

8 optimal fiber length $\left.l_{j}^{M_{0}}\right), l_{j}^{M}$ and $v_{j}^{M}$ are the current length of the muscle fiber and the

9 current shortening velocity of the muscle fiber (depending on the kinematic parameters $\left.q_{k}, \dot{q}_{k}\right)$. Moreover, $f_{j}^{M_{a}}\left(l_{j}^{M}\right)$ and $f_{j}^{M_{v}}\left(v_{j}^{M}\right)$ are respectively the active force-length and force-

11 velocity relationships (representative of the contractile component of the fiber), $f_{j}^{M_{p}}\left(l_{j}^{M}\right)$ is the passive force-length relationship (representative of the elastic component of the muscle fiber). These relationships are usually described using cubic splines, but can also be described through the following equations (Davy \& Audu, 1987; Selk Ghafari, Meghdari, \& Vossoughi, 2009):

$17 \quad f_{j}^{M_{p}}\left(l_{j}^{M}\right)=e^{10 \cdot\left(l_{j}^{M}-1\right)} / e^{5}$

Finally, this model can be extended by describing the variations of the pennation angle $\varphi_{j}$ around the pennation angle at muscle optimal fiber length $\varphi_{j}^{0}$ (Scott \& Winter, 1991), 
1 involving the variations of the muscle optimal fiber length $l_{j}^{M_{0}}$ (Huijing, 1996) since

$2 \varphi_{j}=\sin ^{-1}\left(l_{j}^{M_{0}} \sin \left(\varphi_{j}^{0}\right) / l_{j}^{M}\right)$, and by introducing the fact that a force is transmitted by the

3 tendon only when the tendon length is greater than the tendon slack length $I_{j}^{T s}$ (otherwise the

4 musculo-tendon force is zero as described by Zajac (Zajac, 1989)).

5

6

7

\subsection{Skeletal dynamics model}

The musculo-tendon forces $f_{j}$ are the unknowns of the dynamic equations of the musculoskeletal system. Two basic hypotheses are generally made: the musculo-tendon forces are the only forces that produce joint power and all the musculo-tendon forces produce joint power. As a consequence, the joint reaction forces (i.e., the sum of the contact forces and ligament forces) are assumed to be applied at the reduction points of the net joint moments (i.e., arbitrary fixed or optimized joint centres (Li, Pierce, \& Herndon, 2006)). In this case, for a system with $n$ joints, $m$ muscle lines of action, and $p$ DoF, these equations can be written as:

$$
\left[\begin{array}{c}
\mathbf{M}_{1} \cdot \mathbf{e}_{1} \\
\vdots \\
\mathbf{M}_{n} \cdot \mathbf{e}_{p}
\end{array}\right]=\left[\begin{array}{lll}
\mathbf{L}_{1}^{f} & \cdots & \mathbf{L}_{m}^{f}
\end{array}\right]\left[\begin{array}{c}
f_{1} \\
\vdots \\
f_{m}
\end{array}\right]
$$

where $\mathbf{M}_{i}(i=1: n)$ are net joint moments, $\mathbf{e}_{k}(k=1: p)$ are the DoF axes, $\mathbf{L}_{j}^{f}(j=1: m)$ are the muscle lever arms matrices and $f_{j}$ the musculo-tendon force amplitudes. These amplitudes cannot be computed by simple inversion of Equation (7) because $m>p$. Typically, $\mathbf{e}_{k}$ is a selected axis from the inertial, segment or joint coordinate systems assumed to be representative of the DoF axis (Cleather \& Bull, 2011b; Crowninshield \& Brand, 1981; Fraysse, Dumas, Cheze, \& Wang, 2009; Patriarco, Mann, Simon, \& Mansour, 1981). The muscle lever arms must be computed geometrically with respect to the same axis. 
1 The element $L_{k j}^{f}$ of the muscle lever arms matrices is the projection on the axis $\mathbf{e}_{k}$ of the cross

2 product of the vector from the reduction point of the joint moment to its orthogonal projection

3 on the $j^{\text {th }}$ muscle line of action and the vector of orientation $\mathbf{u}_{j}^{f}$ of this line of action. The

4 element $L_{k j}^{f}$ is null for the muscles not crossing the joint. Equation (7) can be written joint by

5 joint $(i=1: n)$, but it is important to consider all joints at the same time in order to manage the

6 bi-articular muscles (Cleather, Goodwin, \& Bull, 2011; Fraysse et al., 2009). The net joint

7 moments $\mathbf{M}_{i}$ are obtained by classical (i.e., recursive Newton-Euler) inverse dynamics, but

8 the motor joint moments (i.e., $\mathbf{M}_{i} \cdot \mathbf{e}_{k}$ ) can be directly computed all together by the Lagrange

9 equations (with $p$ parameters $q_{k}$ representing the angles about $\mathbf{e}_{k}$ ), giving:

10

$$
\left[\begin{array}{c}
\frac{d}{d t}\left(\frac{\partial E}{\partial \dot{q}_{1}}\right)-\frac{\partial E}{\partial q_{1}}-\frac{\partial P}{\partial \dot{q}_{1}} \\
\vdots \\
\frac{d}{d t}\left(\frac{\partial E}{\partial \dot{q}_{p}}\right)-\frac{\partial E}{\partial q_{p}}-\frac{\partial P}{\partial \dot{q}_{p}}
\end{array}\right]=\left[\begin{array}{lll}
\mathbf{L}_{1}^{f} & \cdots & \mathbf{L}_{m}^{f}
\end{array}\right]\left[\begin{array}{c}
f_{1} \\
\vdots \\
f_{m}
\end{array}\right]
$$

where $E$ is the kinetic energy of the system, and $P$ the power of the external and gravitational forces. In this form, it is understood that the element $L_{k j}^{f}$ of the muscle lever arms matrices can be computed as the derivative with respect to $q_{k}$ of the power of a muscle force of unitary amplitude $f_{j}$ in the direction $\mathbf{u}_{j}^{f}$ (Pandy, 1999). Conversely to Equation (7), Equation (8) represents differential equations (i.e., with explicitly $q_{k}, \dot{q}_{k}, \ddot{q}_{k}$ ), allowing both inverse and forward computations. However, in the case of forward computations, a specific method is needed in order to compute the power $P_{0}$ at the contact of the foot on the ground (Dorn, Lin, \& Pandy, 2012; Lin, Kim, \& Pandy, 2011). 
1 Once the musculo-tendon force amplitudes $f_{j}$ are computed (see Section 3), the joint reaction

2 forces can be simply deduced joint by joint as the difference between the net joint forces $\mathbf{F}_{i}$

3 and the sum of the musculo-tendon forces of the muscles crossing the joint. Generally, these

4 joint reaction forces are assumed to represent the joint contact forces. Similarly, the joint

5 reaction moments are the difference between the net joint moments $\mathbf{M}_{i}$ and the sum of the

6 motor joint moments. However, especially for the knee joint, by introducing an adapted joint

7 geometry, both joint contact forces and ligament forces may be computed (Cleather \& Bull,

$8 \quad 2011 a ;$ Morrison, 1970):

$9\left\{\begin{array}{c}\mathbf{F}_{i} \\ \mathbf{M}_{i}\end{array}-\left\{\begin{array}{c}\sum f_{j} \mathbf{u}_{j} \\ \sum\left(\mathbf{M}_{i} \cdot \mathbf{e}_{k}\right) \mathbf{e}_{k}\end{array}=\left[\begin{array}{lll}\mathbf{L}_{1}^{g} & \cdots & \mathbf{L}_{r}^{g}\end{array}\right]\left[\begin{array}{c}g_{1} \\ \vdots \\ g_{r}\end{array}\right]\right.\right.$

(Equation 9)

where $\mathbf{L}_{l}^{g}(l=1: r)$ are the contact and ligament lever arms (or projection) matrices and $g_{l}$ the contact and ligament force amplitudes. The contact and ligament lever arms are computed geometrically in the same way as the muscle lever arms (i.e., knowing the position and orientation $\mathbf{u}_{l}^{g}$ of the contacts or of the ligament lines of action). However, the total number of contact and ligament forces that can be computed is $r=6^{*} n-p$ and an adapted (i.e., simplified) joint geometry is used. The joint reactions or the joint contact forces and the ligament forces can be also obtained from the Lagrange equations by modifying the parameters $q_{k}(k=1: p+r)$ in order to introduce kinematic constraints $\Phi_{l}$ (e.g., concurrent points, constant lengths) and Lagrange multipliers $\lambda_{l}$ (Damsgaard, Rasmussen, Christensen, 
$\left[\begin{array}{c}\frac{d}{d t}\left(\frac{\partial E}{\partial \dot{q}_{1}}\right)-\frac{\partial E}{\partial q_{1}}-\frac{\partial Q}{\partial \dot{q}_{1}} \\ \vdots \\ \frac{d}{d t}\left(\frac{\partial E}{\partial \dot{q}_{p+r}}\right)-\frac{\partial E}{\partial q_{p+r}}-\frac{\partial Q}{\partial \dot{q}_{p+r}}\end{array}\right]-\left[\begin{array}{lll}\mathbf{L}_{1}^{f} & \cdots & \mathbf{L}_{m}^{f}\end{array}\right]\left[\begin{array}{c}f_{1} \\ \vdots \\ f_{m}\end{array}\right]=\left[\frac{\partial \mathbf{\Phi}}{\partial \mathbf{q}}\right]^{T}\left(\begin{array}{c}\lambda_{1} \\ \vdots \\ \lambda_{r}\end{array}\right)$

(Equation 10)

2 where $\left[\frac{\partial \mathbf{\Phi}}{\partial \mathbf{q}}\right]$ is the Jacobian matrix of the kinematic constraints. The Lagrange multipliers $\lambda_{I}$

$3 \quad(l=1: r)$ are linearly related to $g_{l}$ (Moissenet et al., 2012). Conversely to the other equations,

4 Equation (10) requires consistent kinematics (i.e., $q_{k}, \dot{q}_{k}, \ddot{q}_{k}$ must satisfy $\boldsymbol{\Phi}, \dot{\Phi}, \ddot{\boldsymbol{\Phi}}$

5 respectively) obtained by specific methods (Alonso, Cuadrado, Lugrís, \& Pintado, 2010;

6 Andersen, Damsgaard, \& Rasmussen, 2009; Moissenet et al., 2012; Silva \& Ambrósio, 2002).

7 The transformation from Equation (10) to Equation (8) is simply obtained by multiplying all

8 terms by a projection matrix (Dumas et al., 2012; Moissenet et al., 2012), made of the $p$ basis

9 vector of the nullspace of the Jacobian matrix of the kinematic constraints.

In case of detailed geometry (Guess, Liu, Bhashyam, \& Thiagarajan, 2012; Pandy, Sasaki, \& Kim, 1998; Shelburne, Torry, \& Pandy, 2005), the joints are modeled with deformable elements (i.e., hertz contact, force-strain ligament curves). This is equivalent to a $6 * n$ DoF system with a penalty-based method for the kinematic constraints $\Phi_{l}(l=1$ : $r$, with $r$ unlimited):

$$
\left[\begin{array}{c}
\frac{d}{d t}\left(\frac{\partial E}{\partial \dot{q}_{1}}\right)-\frac{\partial E}{\partial q_{1}}-\frac{\partial Q}{\partial \dot{q}_{1}} \\
\vdots \\
\frac{d}{d t}\left(\frac{\partial E}{\partial \dot{q}_{6^{* n}}}\right)-\frac{\partial E}{\partial q_{6^{*} n}}-\frac{\partial Q}{\partial \dot{q}_{6^{* n}}}
\end{array}\right]-\left[\begin{array}{lll}
\mathbf{L}_{1}^{f} & \cdots & \mathbf{L}_{m}^{f}
\end{array}\right]\left[\begin{array}{c}
f_{1} \\
\vdots \\
f_{m}
\end{array}\right]=\left[\frac{\partial \mathbf{\Phi}}{\partial \mathbf{q}}\right]^{T}\left(\begin{array}{c}
K_{1} \Phi_{1} \\
\vdots \\
K_{r} \Phi_{r}
\end{array}\right)
$$
where $K_{l}$ is the contact or ligament stiffness. Conversely to $g_{l}$ in Equation (9) and to $\lambda_{l}$ in Equation (10), $K_{l} \Phi_{l}$ in Equation (11) can be computed independently of the musculo-tendon 
1 force amplitudes $f_{j}$ (i.e., it only depends on the parameters $q_{k}$ ) and seems specifically

2 dedicated for forward computations. Moreover, Equation (11) and forward dynamics assisted

3 data tracking (see Section 3.3) is the unique dynamic method to overcome the two basic

4 hypotheses on the musculo-tendon forces and joint power (i.e., the musculo-tendon forces are

5 the only forces that produce joint power and all the musculo-tendon forces produce joint 6 power).

\section{Prediction of the individual musculo-tendon and joint reaction forces}

It is important to note that all methods (Figure 2 to 5) need to proceed some dynamics (i.e., recursive newton-Euler or Lagrange, inverse or forward). Moreover, all methods include an optimization (i.e., minimization of an objective function or of the errors on target values).

However, inverse and forward methods seem to provide comparable results (Anderson \& Pandy, 2001; Lin, Dorn, Schache, \& Pandy, 2012). The skeletal dynamics model is required for all methods (i.e., static optimization, EMG-to-force, forward dynamics assisted data tracking). The musculo-tendon dynamics model is used if the muscle activations rather the musculo-tendon forces are estimated and the contraction dynamics model is used if these muscle activations are obtained from the electromyographic (EMG) data.

Depending on the method, the performance is commonly assessed by qualitative comparison of muscle activations or musculo-tendon forces patterns and EMG data (Dickerson, Hughes, \& Chaffin, 2008), by the final errors on the target values (i.e., kinematic or motor joint moment) (Shao et al., 2009). For all methods, the validation can be done at the level of the joint contact forces using instrumented prostheses (Brand et al., 1994; Fregly, Besier, et al., 
2012; Lu et al., 1998; Lundberg, Foucher, Andriacchi, \& Wimmer, 2012; Modenese, Phillips, \& Bull, 2011; Stansfield et al., 2003).

\subsection{Static optimization}

The muscular load sharing problem is solved for each instant in time, by minimizing an objective function, subject to dynamic constraints (Equations 7 or 8) and lower and upper bounds (Figure 2). A typical objective function is the sum of forces $f_{j}$ squared weigthed by the muscles physiological cross section area $S_{j}$ squared (Crowninshield \& Brand, 1981). A variant of the inverse dynamics-based static optimization (Figure 3) includes the muscle contraction model and minimizes an objective function depending on the muscle activations (Lenaerts et al., 2008; Pettersson, Bartonek, \& Gutierrez-Farewik, 2012). In both cases, the joint reaction forces are then deduced from the musculo-tendon forces (Equations 9 or 10).

Static optimization is computationally efficient. It can be seen as an additional step flowing inverse dynamics. In case of no muscular redundancy, it could be treated as a simple inversion of the dynamics (Gignoux, Cheze, Carret, \& Dimnet, 1994; Morrison, 1970; Smidt, 1973). Nevertheless, as far as inverse dynamics is involved, the inaccuracies of experimental data (e.g., kinematics $q_{k}, \dot{q}_{k}, \ddot{q}_{k}$ ) have been identified as weaknesses of this method (Riemer, Hsiao-Wecksler, \& Zhang, 2008).

In case of muscular redundancy, another point, specific to this method, is the choice of the objective function. The sum of forces $f_{j}$ squared has been widely accepted for prediction of musculo-tendon forces in lower extremity during walking but is hardly subject's physiology and pathology specific. In addition to the sensitivity of the estimated musculo-tendon forces to the musculo-skeletal models parameters (see Section 4), static optimization also reveals a 
1 high sensitivity to the objective function (Challis, 1997; Cleather \& Bull, 2011a;

2 Crowninshield \& Brand, 1981; Modenese et al., 2011; Praagman, Chadwick, Van Der Helm,

3 \& Veeger, 2006; Rasmussen, Damsgaard, \& Voigt, 2001) and to the constraints. Some of

4 these constraints include EMG information (e.g., co-contraction ratios (Amarantini, Rao, \&

5 Berton, 2010; Brookham, Middlebrook, Grewal, \& Dickerson, 2011)) in order to produce 6 physiological muscular solutions.

3.2 EMG-to-force

The EMG signal can be also processed to directly obtain the musculo-tendon force. EMG data $e_{j}(t)$ are first processed (i.e., normalized, rectified) and transformed using a recursive filter (Buchanan et al., 2004; Lloyd \& Besier, 2003) to obtain the muscle excitation $u_{j}(t)$ :

$u_{j}(t)=\alpha \cdot e_{j}(t-d)-\beta_{1} \cdot u_{j}(t-1)-\beta_{2} \cdot u_{j}(t-2)$

(Equation 12)

where $\alpha, \beta_{1}$ and $\beta_{2}$ are coefficients that are determined during the calibration procedure of the EMG-driven model. Finally, $d$ is the electromechanical delay of the muscle.

Then, by using the contraction dynamics model and the musculo-tendon dynamics model (Equations 1 to 6), the individual musculo-tendon forces are estimated (Figure 4). The joint reaction forces are then deduced from the musculo-tendon forces (Equations 9 or 10). This procedure usually involves the calibration of the musculo-skeletal models by adjusting subject-specific model parameters (i.e., typically $\varphi_{j}, l_{j}^{M_{0}}, A$ ) (Buchanan et al., 2004; Lloyd \& Besier, 2003). This can be done by minimizing the difference between the motor joint moments (i.e., $\mathbf{M}_{i} \cdot \mathbf{e}_{k}$ computed through an inverse dynamics or measured under very specific conditions like isometric contractions) and those computed from the estimated musculotendon forces (Equations 7 or 8). The advantages of EMG-driven method rely on the use of 
1 the measured muscle activity and so this method implicitly accounts for the subject's

2 individual activation patterns, providing physiological co-contractions. Their main limits are

3 the important number of parameters involved (Menegaldo \& de Oliveira, 2009), the influence

4 of electrode placement and tissue conductivity (De Luca, 1997) and the influence of EMG

5 processing on the computation of the musculo-tendon forces under dynamic conditions

6 (Disselhorst-Klug, Schmitz-Rode, \& Rau, 2009). Moreover, only the surface muscle can be

7 easily included in such method. Furthermore, these methods require an extensive calibration

8 procedure encompassing a wide range of contractile conditions to adjust most of the model

9 parameters (Amarantini \& Martin, 2004; Gerus, Rao, Buchanan, \& Berton, 2010; Lloyd \&

10 Besier, 2003).

\subsection{Forward dynamics assisted data tracking}

An initial set of muscle activations are fed into a musculo-tendon dynamics model (Equations 2 to 6 ) and into forward dynamics (Equations 10 or 11). Both kinematics (i.e., $q_{k}, \dot{q}_{k}, \ddot{q}_{k}$ ) and joint reaction forces (i.e., $\lambda_{l}$ or $K_{l} \Phi_{l}$ ) are computed at each time frame by numerical integration. The solution is compared against experimental data (Figure 5) and the process is iterated by updating the muscle activations that best reproduce the experimental kinematics (Lin et al., 2012; McLean, Su, \& van den Bogert, 2003; Neptune, McGowan, \& Kautz, 2009). A contact model is specifically required in this method to estimate the external forces as a function of the kinematics.

This method may be advantageous due to the more straightforward inclusion of muscle contractions within the solution when compared to static optimization (Happee, 1994), and it is less sensitive to experimental errors on kinematics. No force plate data are required. It also 
1 allows including detailed joints models with deformable elements (i.e., hertz contact, force-

2 strain ligament curves) (Guess et al., 2012; Pandy et al., 1998; Shelburne et al., 2005).

3 The main limits are the same as the EMG-driven method but are also related to the quality of

4 the contact model required to estimate the external forces (Dorn et al., 2012). The technique is

5 also computationally involved due to multiple integrations of the dynamic equation across all time frames. As far as different muscle activations may provide the same kinematics (i.e., due to the muscular redundancy) the solution is also sensitive to the initial guess.

\section{Personalization of the musculo-skeletal models parameters}

Whatever the method used to estimate the individual musculo-tendon forces and the joint reaction forces, the musculo-skeletal models are composed of a large number of parameters (e.g., $A, \varphi_{j}, f_{j}^{M_{0}}, f_{j}^{M_{a}}, f_{j}^{M_{v}}, f_{j}^{M_{p}}, l_{j}^{M_{0}}, l_{j}^{T s}, \mathbf{e}_{k}, \mathbf{u}_{j}^{f}, S_{j}, \mathbf{u}_{l}^{g}, \Phi_{l}, K_{l}$, in Equations 1 to 12 and Figures 1 to 5).

This can be considered as an advantage since that allows a precise adjustment of the models, but it is a real problem since these parameters cannot be personalized easily. Moreover, the simulation results are highly sensitive to all of these parameters: muscle-tendon properties and muscular geometry (Ackland, Lin, \& Pandy, 2012; Cleather \& Bull, 2010; De Groote, Van Campen, Jonkers, \& De Schutter, 2010; Raikova \& Prilutsky, 2001; Redl, Gfoehler, \& Pandy, 2007; Scheys, Desloovere, Suetens, \& Jonkers, 2011; Scovil \& Ronsky, 2006; Xiao \& Higginson, 2010), joint geometry, joint DoFs and stiffness (Amankwah, Triolo, Kirsch, \& Audu, 2006; Cleather \& Bull, 2011b; Delp \& Maloney, 1993; Dumas et al., 2012; Glitsch \& 
1 Xiao \& Higginson, 2008). On the overall, most of the models parameters have been initially

2 defined in the literature from cadaveric measurements (Delp et al., 1990; Klein Horsman, Koopman, van der Helm, Prose, \& Veeger, 2007; Pandy, Sasaki, \& Kim, 1997).

4

5 Some muscular parameters (e.g., $l_{j}^{M_{0}}, l_{j}^{T s}, \varphi_{j}$ ) can be obtained by ultrasound(Li, Tong, Hu, Hung, \& Koo, 2009). Methods also exist to adjust other muscular parameters (Siebert, Sust,

Thaller, Tilp, \& Wagner, 2007). For example, $f_{j}^{M_{0}}$ can be estimated during clinical testing by asking the subject to produce a maximum force in an isometric condition and by recording the resulting EMG signal (Bogey, Perry, \& Gitter, 2005). Then, based on this value, the curve of $f_{j}^{M_{a}}, f_{j}^{M_{v}}$ and $f_{j}^{M_{p}}$ (Figure 6a) can be scaled to the subject. Concerning these parameters, the procedures used to scale the model to the subject have many limits making them difficult to generalize. Indeed, medical imaging technologies are costly and time-consuming and clinical testing remains very patient and clinician dependant, introducing imprecision during measurements (Colombo et al., 2000; Jepsen, Laursen, Larsen, \& Hagert, 2004). To overcome these limits, some analytical methods have been proposed (Winby, Lloyd, \& Kirk, 2008). As many studies showed that the prediction of individual musculo-tendon forces is highly sensitive to these parameters, a special attention should be given to the results when using such methods.

The musculo-tendon units, modeled as straight lines joining their origin to their insertion, with multiple lines of action to model broad muscles, including via points (Figure 6b) and wrapping surface algorithms when necessary, can be personalized with medical imaging, such as IRM (Albracht, Arampatzis, \& Baltzopoulos, 2008; Blemker, Asakawa, Gold, \& Delp, 

.

2007; Fregly, Boninger, \& Reinkensmeyer, 2012; Jolivet et al., 2008; Scheys, Loeckx, Spaepen, Suetens, \& Jonkers, 2009; Taddei et al., 2012). Presently, a segmentation of medical images based on a deformable template can be used to obtain the 3D geometry of the subject's muscle as well as of the ligaments (e.g., $\mathbf{u}_{j}^{f}, \mathbf{u}_{l}^{g}$ ). However, simple scaling ratios are more generally used to fit the generic models to the subject's anthropometry.

Conversely to the muscle parameters, the kinematic (i.e., $\mathbf{e}_{k}, \Phi_{l}$ ) and dynamic (i.e., $K_{l}$ ) parameters of the joints are not scaled nor personalized. For instance, coupled degrees of freedom are the prescribed functions (Figure 6c) that link the secondary displacements and rotations to the flexion-extension angle (Delp et al., 1990) or kinematic constraints are issued from a generic parallel mechanism (Dumas et al., 2012; Moissenet et al., 2012). Moreover, in detailed joint models, even if the bones, ligaments and menisci geometry might be personalized using medical imaging, the contact stiffness and the force-strain ligament curves (Figure 6d) are taken from cadaveric experiments.

\section{Conclusion}

The possibility to obtain quantitative estimates of musculo-tendon forces and joint reaction forces (i.e., contact forces and ligament forces) during movement has significant clinical potential, but before considering such clinical applications, it is important to balance the potential usefulness of these approaches against their limitations reviewed in this paper. Using a rigorous experimental protocol, an appropriate musculo-skeletal dynamic model and integrating EMG data seem to be of great importance. Subject-specific models are also essential to develop for clinical populations with bone deformities or altered muscle properties, like cerebral palsy children or post-stokes adults (Piazza, 2006). Nevertheless, the 
1 computation of the musculo-tendon forces and joint reaction forces depends on a great

2 number of parameters, most of them difficult or impossible to adjust to the studied patient.

3 Moreover, the validity of model-based musculo-tendon force prediction must be better

4 established. Some promising techniques based on ultrasound (Bouillard, Nordez, \& Hug,

5 2011; Farron, Varghese, \& Thelen, 2009; Pourcelot, Defontaine, Ravary, Lemâtre, \& Crevier-

6 Denoix, 2005) could be able to estimate or measure non-invasively the superficial tendons

7 strength or force. Data sets coming from patients implanted with force-measuring prostheses

8 have also been provided to the musculo-skeletal modelling research community to help

9 validating the joint contact forces (Fregly, Besier, et al., 2012; Modenese et al., 2011). 


\section{References}

Ackland, D. C., Lin, Y. C., \& Pandy, M. G. (2012). Sensitivity of model predictions of muscle function to changes in moment arms and muscle-tendon properties: a Monte-Carlo analysis. J Biomech, 45(8), 1463-1471.

Albracht, K., Arampatzis, A., \& Baltzopoulos, V. (2008). Assessment of muscle volume and physiological cross-sectional area of the human triceps surae muscle in vivo. J Biomech, 41(10), 2211-2218.

Alonso, F. J., Cuadrado, J., Lugrís, U., \& Pintado, P. (2010). A compact smoothing-differentiation and projection approach for the kinematic data consistency of biomechanical systems. Multibody System Dynamics, 24(1), 67-80.

Amankwah, K., Triolo, R., Kirsch, R., \& Audu, M. (2006). A model-based study of passive joint properties on muscle effort during static stance. J Biomech, 39(12), 2253-2263.

Amarantini, D., \& Martin, L. (2004). A method to combine numerical optimization and EMG data for the estimation of joint moments under dynamic conditions. J Biomech, 37(9), 1393-1404.

Amarantini, D., Rao, G., \& Berton, E. (2010). A two-step EMG-and-optimization process to estimate muscle force during dynamic movement. J Biomech, 43(9), 1827-1830.

Andersen, M. S., Damsgaard, M., \& Rasmussen, J. (2009). Kinematic analysis of over-determinate biomechanical systems. Comput Methods Biomech Biomed Engin, 12(4), 371-384.

Anderson, F. C., \& Pandy, M. G. (2001). Static and dynamic optimization solutions for gait are practically equivalent. J Biomech, 34(2), 153-161.

Besier, T. F., Gold, G. E., Beaupre, G. S., \& Delp, S. L. (2005). A modeling framework to estimate patellofemoral joint cartilage stress in vivo. Med Sci Sports Exerc, 37(11), 1924-1930.

Bey, M. J., \& Derwin, K. A. (2012). Measurement of in vivo tendon function. J Shoulder Elbow Surg, 21(2), 149-157.

Blemker, S. S., Asakawa, D. S., Gold, G. E., \& Delp, S. L. (2007). Image-based musculoskeletal modeling: applications, advances, and future opportunities. J Magn Reson Imaging, 25(2), 441-451.

Bogey, R. A., Perry, J., \& Gitter, A. J. (2005). An EMG-to-force processing approach for determining ankle muscle forces during normal human gait. IEEE Trans Neural Syst Rehabil Eng, 13(3), 302-310.

Bouillard, K., Nordez, A., \& Hug, F. (2011). Estimation of individual muscle force using elastography. PLoS ONE, 6(12).

Brand, R. A., Pedersen, D. R., Davy, D. T., Kotzar, G. M., Heiple, K. G., \& Goldberg, V. M. (1994). Comparison of hip force calculations and measurements in the same patient. J Arthroplasty, 9(1), 45-51.

Brookham, R. L., Middlebrook, E. E., Grewal, T. J., \& Dickerson, C. R. (2011). The utility of an empirically derived co-activation ratio for muscle force prediction through optimization. $\mathrm{J}$ Biomech, 44(8), 1582-1587.

Buchanan, T. S., Lloyd, D. G., Manal, K., \& Besier, T. F. (2004). Neuromusculoskeletal modeling: estimation of muscle forces and joint moments and movements from measurements of neural command. J Appl Biomech, 20(4), 367-395.

Cappozzo, A., Catani, F., Croce, U. D., \& Leardini, A. (1995). Position and orientation in space of bones during movement: anatomical frame definition and determination. Clin Biomech (Bristol, Avon), 10(4), 171-178. 
Challis, J. H. (1997). Producing physiologically realistic individual muscle force estimations by imposing constraints when using optimization techniques. Med Eng Phys, 19(3), 253-261.

Cleather, D. J., \& Bull, A. M. (2011a). An optimization-based simultaneous approach to the determination of muscular, ligamentous, and joint contact forces provides insight into musculoligamentous interaction. Ann Biomed Eng, 39(7), 1925-1934.

Cleather, D. J., \& Bull, A. M. J. (2010). Lower-extremity musculoskeletal geometry affects the calculation of patellofemoral forces in vertical jumping and weightlifting. Proc IME H J Eng Med, 224(9), 1073-1083.

Cleather, D. J., \& Bull, A. M. J. (2011b). Knee and hip joint forces - sensitivity to the degrees of freedom classification at the knee. Proc IME H J Eng Med, 225(6), 621-626.

Cleather, D. J., Goodwin, J. E., \& Bull, A. M. (2011). An optimization approach to inverse dynamics provides insight as to the function of the biarticular muscles during vertical jumping. Ann Biomed Eng, 39(1), 147-160.

Colombo, R., Mazzini, L., Mora, G., Parenzan, R., Creola, G., Pirali, I., \& Minuco, G. (2000). Measurement of isometric muscle strength: a reproducibility study of maximal voluntary contraction in normal subjects and amyotrophic lateral sclerosis patients. Med Eng Phys, 22(3), 167-174.

Crowninshield, R. D., \& Brand, R. A. (1981). A physiologically based criterion of muscle force prediction in locomotion. J Biomech, 14(11), 793-801.

Damsgaard, M., Rasmussen, J., Christensen, S. T., Surma, E., \& de Zee, M. (2006). Analysis of musculoskeletal systems in the AnyBody Modeling System. Simulation Modelling Practice and Theory, 14(8), 1100-1111.

Davy, D. T., \& Audu, M. L. (1987). A dynamic optimization technique for predicting muscle forces in the swing phase of gait. J Biomech, 20(2), 187-201.

De Groote, F., Van Campen, A., Jonkers, I., \& De Schutter, J. (2010). Sensitivity of dynamic simulations of gait and dynamometer experiments to hill muscle model parameters of knee flexors and extensors. J Biomech, 43(10), 1876-1883.

De Luca, C. J. (1997). The use of surface electromyography in biomechanics. J Appl Biomech, 13(2), 135-163.

Delp, S. L., Loan, J. P., Hoy, M. G., Zajac, F. E., Topp, E. L., \& Rosen, J. M. (1990). An interactive graphics-based model of the lower extremity to study orthopaedic surgical procedures. IEEE Trans Biomed Eng, 37(8), 757-767.

Delp, S. L., \& Maloney, W. (1993). Effects of hip center location on the moment-generating capacity of the muscles. J Biomech, 26(4-5), 485-499.

Dickerson, C. R., Hughes, R. E., \& Chaffin, D. B. (2008). Experimental evaluation of a computational shoulder musculoskeletal model. Clin Biomech (Bristol, Avon), 23(7), 886-894.

Disselhorst-Klug, C., Schmitz-Rode, T., \& Rau, G. (2009). Surface electromyography and muscle force: limits in sEMG-force relationship and new approaches for applications. Clin Biomech (Bristol, Avon), 24(3), 225-235.

Dorn, T. W., Lin, Y. C., \& Pandy, M. G. (2012). Estimates of muscle function in human gait depend on how foot-ground contact is modelled. Computer Methods in Biomechanics and Biomedical Engineering, 15(6), 657-668.

Dumas, R., Moissenet, F., Gasparutto, X., \& Cheze, L. (2012). Influence of joint models on lowerlimb musculo-tendon forces and three-dimensional joint reaction forces during gait. Proc Inst Mech Eng H, 226(2), 146-160.

Ebashi, S. (1972). Calcium ions and muscle contraction. Nature, 240(5378), 217-218. 
Farron, J., Varghese, T., \& Thelen, D. G. (2009). Measurement of tendon strain during muscle twitch contractions using ultrasound elastography. IEEE Transactions on Ultrasonics, Ferroelectrics, and Frequency Control, 56(1), 27-35.

Fleming, B. C., \& Beynnon, B. D. (2004). In vivo measurement of ligament/tendon strains and forces: a review. Ann Biomed Eng, 32(3), 318-328.

Fraysse, F., Dumas, R., Cheze, L., \& Wang, X. (2009). Comparison of global and joint-to-joint methods for estimating the hip joint load and the muscle forces during walking. J Biomech, 42(14), 2357-2362.

Fregly, B. J., Besier, T. F., Lloyd, D. G., Delp, S. L., Banks, S. A., Pandy, M. G., \& D'Lima, D. D. (2012). Grand challenge competition to predict in vivo knee loads. J Orthop Res, 30(4), 503513.

Fregly, B. J., Boninger, M. L., \& Reinkensmeyer, D. J. (2012). Personalized neuromusculoskeletal modeling to improve treatment of mobility impairments: a perspective from European research sites. J Neuroeng Rehabil, 9, 18.

Gerus, P., Rao, G., Buchanan, T. S., \& Berton, E. (2010). A clinically applicable model to estimate the opposing muscle groups contributions to isometric and dynamic tasks. Ann Biomed Eng, 38(7), 2406-2417.

Gignoux, P., Cheze, L., Carret, J. P., \& Dimnet, J. (1994). Hip joint loading computation of a walking patient during stance phase. Clinical Materials, 15(4), 247-252.

Glitsch, U., \& Baumann, W. (1997). The three-dimensional determination of internal loads in the lower extremity. J Biomech, 30(11-12), 1123-1131.

Guess, T. M., Liu, H., Bhashyam, S., \& Thiagarajan, G. (2012). A multibody knee model with discrete cartilage prediction of tibiofemoral contact mechanics. Computer Methods in Biomechanics and Biomedical Engineering, In press.

Happee, R. (1994). Inverse dynamic optimization including muscular dynamics, a new simulation method applied to goal directed movements. Journal of Biomechanics, 27(7), 953-960.

Hoy, M. G., Zajac, F. E., \& Gordon, M. E. (1990). A musculoskeletal model of the human lower extremity: the effect of muscle, tendon, and moment arm on the moment-angle relationship of musculotendon actuators at the hip, knee, and ankle. J Biomech, 23(2), 157-169.

Huijing, P. A. (1996). Important experimental factors for skeletal muscle modelling: non-linear changes of muscle length force characteristics as a function of degree of activity. Eur $\mathrm{J}$ Morphol, 34(1), 47-54.

Jepsen, J. R., Laursen, L. H., Larsen, A. I., \& Hagert, C. G. (2004). Manual strength testing in 14 upper limb muscles: A study of inter-rater reliability. Acta Orthopaedica Scandinavica, 75(4), $442-448$.

Jolivet, E., Daguet, E., Pomero, V., Bonneau, D., Laredo, J. D., \& Skalli, W. (2008). Volumic patientspecific reconstruction of muscular system based on a reduced dataset of medical images. Computer Methods in Biomechanics and Biomedical Engineering, 11(3), 281-290.

Klein Horsman, M. D., Koopman, H. F., van der Helm, F. C., Prose, L. P., \& Veeger, H. E. (2007). Morphological muscle and joint parameters for musculoskeletal modelling of the lower extremity. Clin Biomech (Bristol, Avon), 22(2), 239-247.

Komi, P. V. (1990). Relevance of in vivo force measurements to human biomechanics. J Biomech, 23 Suppl 1, 23-34.

Lenaerts, G., De Groote, F., Demeulenaere, B., Mulier, M., Van der Perre, G., Spaepen, A., \& Jonkers, I. (2008). Subject-specific hip geometry affects predicted hip joint contact forces during gait. J Biomech, 41(6), 1243-1252.

Li, G., Kawamura, K., Barrance, P., Chao, E. Y., \& Kaufman, K. (1998). Prediction of muscle recruitment and its effect on joint reaction forces during knee exercises. Ann Biomed Eng, 26(4), 725-733. 
Li, G., Pierce, J. E., \& Herndon, J. H. (2006). A global optimization method for prediction of muscle forces of human musculoskeletal system. J Biomech, 39(3), 522-529.

Li, L., Tong, K. Y., Hu, X. L., Hung, L. K., \& Koo, T. K. (2009). Incorporating ultrasound-measured musculotendon parameters to subject-specific EMG-driven model to simulate voluntary elbow flexion for persons after stroke. Clin Biomech (Bristol, Avon), 24(1), 101-109.

Lin, Y. C., Dorn, T. W., Schache, A. G., \& Pandy, M. G. (2012). Comparison of different methods for estimating muscle forces in human movement. Proc Inst Mech Eng H, 226(2), 103-112.

Lin, Y. C., Kim, H. J., \& Pandy, M. G. (2011). A computationally efficient method for assessing muscle function during human locomotion. International Journal for Numerical Methods in Biomedical Engineering, 27(3), 436-449.

Lloyd, D. G., \& Besier, T. F. (2003). An EMG-driven musculoskeletal model to estimate muscle forces and knee joint moments in vivo. J Biomech, 36(6), 765-776.

Lu, T. W., O'Connor, J. J., Taylor, S. J., \& Walker, P. S. (1998). Validation of a lower limb model with in vivo femoral forces telemetered from two subjects. J Biomech, 31(1), 63-69.

Lundberg, H. J., Foucher, K. C., Andriacchi, T. P., \& Wimmer, M. A. (2012). Direct comparison of measured and calculated total knee replacement force envelopes during walking in the presence of normal and abnormal gait patterns. J Biomech, 45(6), 990-996.

McLean, S. G., Su, A., \& van den Bogert, A. J. (2003). Development and validation of a 3-D model to predict knee joint loading during dynamic movement. J Biomech Eng, 125(6), 864-874.

Menegaldo, L. L., \& de Oliveira, L. F. (2009). Effect of muscle model parameter scaling for isometric plantar flexion torque prediction. J Biomech, 42(15), 2597-2601.

Modenese, L., Phillips, A. T., \& Bull, A. M. (2011). An open source lower limb model: Hip joint validation. J Biomech, 44(12), 2185-2193.

Moissenet, F., Cheze, L., \& Dumas, R. (2012). Anatomical kinematic constraints: consequences on musculo-tendon forces and joint reactions. Multibody Syst Dyn, 28(1-2), 125-141.

Morrison, J. B. (1970). The mechanics of the knee joint in relation to normal walking. Journal of Biomechanics, 3(1), 51-61.

Neptune, R. R., McGowan, C. P., \& Kautz, S. A. (2009). Forward dynamics simulations provide insight into muscle mechanical work during human locomotion. Exerc Sport Sci Rev, 37(4), 203-210.

Pandy, M. G. (1999). Moment arm of a muscle force. Exerc Sport Sci Rev, 27, 79-118.

Pandy, M. G., Sasaki, K., \& Kim, S. (1997). A three-dimensional musculoskeletal model of the human knee joint. Part 1: theoretical construct. Comput Methods Biomech Biomed Engin, 1(2), 87108.

Pandy, M. G., Sasaki, K., \& Kim, S. (1998). A Three-Dimensional Musculoskeletal Model of the Human Knee Joint. Part 1: Theoretical Construct. Comput Methods Biomech Biomed Engin, 1(2), 87-108.

Patriarco, A. G., Mann, R. W., Simon, S. R., \& Mansour, J. M. (1981). An evaluation of the approaches of optimization models in the prediction of muscle forces during human gait. $\mathrm{J}$ Biomech, 14(8), 513-525.

Pedersen, D. R., Brand, R. A., \& Davy, D. T. (1997). Pelvic muscle and acetabular contact forces during gait. J Biomech, 30(9), 959-965.

Pettersson, R., Bartonek, A., \& Gutierrez-Farewik, E. M. (2012). Posture strategies generated by constrained optimization. J Biomech, 45(3), 461-468.

Piazza, S. J. (2006). Muscle-driven forward dynamic simulations for the study of normal and pathological gait. J Neuroeng Rehabil, 3. 
Pourcelot, P., Defontaine, M., Ravary, B., Lemâtre, M., \& Crevier-Denoix, N. (2005). A non-invasive method of tendon force measurement. Journal of Biomechanics, 38(10), 2124-2129.

Praagman, M., Chadwick, E. K. J., Van Der Helm, F. C. T., \& Veeger, H. E. J. (2006). The relationship between two different mechanical cost functions and muscle oxygen consumption. Journal of Biomechanics, 39(4), 758-765.

Prilutsky, B. I., \& Zatsiorsky, V. M. (2002). Optimization-based models of muscle coordination. Exerc Sport Sci Rev, 30(1), 32-38.

Pustoc'h, A., Bonnefoy, A., Labesse-Jied, F., Lavigne, A., \& Cheze, L. (2011). Assessment of the influence of foot orthoses in the hip loading conditions during walking: a single case study. Comput Methods Biomech Biomed Engin, 14(4), 389-398.

Raikova, R. T., \& Prilutsky, B. I. (2001). Sensitivity of predicted muscle forces to parameters of the optimization-based human leg model revealed by analytical and numerical analyses. J Biomech, 34(10), 1243-1255.

Rasmussen, J., Damsgaard, M., \& Voigt, M. (2001). Muscle recruitment by the min/max criterion - A comparative numerical study. Journal of Biomechanics, 34(3), 409-415.

Redl, C., Gfoehler, M., \& Pandy, M. G. (2007). Sensitivity of muscle force estimates to variations in muscle-tendon properties. Hum Mov Sci, 26(2), 306-319.

Riemer, R., Hsiao-Wecksler, E. T., \& Zhang, X. (2008). Uncertainties in inverse dynamics solutions: a comprehensive analysis and an application to gait. Gait Posture, 27(4), 578-588.

Scheys, L., Desloovere, K., Suetens, P., \& Jonkers, I. (2011). Level of subject-specific detail in musculoskeletal models affects hip moment arm length calculation during gait in pediatric subjects with increased femoral anteversion. J Biomech, 44(7), 1346-1353.

Scheys, L., Loeckx, D., Spaepen, A., Suetens, P., \& Jonkers, I. (2009). Atlas-based non-rigid image registration to automatically define line-of-action muscle models: a validation study. $\mathrm{J}$ Biomech, 42(5), 565-572.

Scott, S. H., \& Winter, D. A. (1991). A comparison of three muscle pennation assumptions and their effect on isometric and isotonic force. J Biomech, 24(2), 163-167.

Scovil, C. Y., \& Ronsky, J. L. (2006). Sensitivity of a Hill-based muscle model to perturbations in model parameters. J Biomech, 39(11), 2055-2063.

Selk Ghafari, A., Meghdari, A., \& Vossoughi, G. R. (2009). Muscle-driven forward dynamics simulation for the study of differences in muscle function during stair ascent and descent. Proc Inst Mech Eng H, 223(7), 863-874.

Shao, Q., Bassett, D. N., Manal, K., \& Buchanan, T. S. (2009). An EMG-driven model to estimate muscle forces and joint moments in stroke patients. Comput Biol Med, 39(12), 1083-1088.

Shelburne, K. B., Torry, M. R., \& Pandy, M. G. (2005). Muscle, ligament, and joint-contact forces at the knee during walking. Medicine and Science in Sports and Exercise, 37(11), 1948-1956.

Siebert, T., Sust, M., Thaller, S., Tilp, M., \& Wagner, H. (2007). An improved method to determine neuromuscular properties using force laws - From single muscle to applications in human movements. Human Movement Science, 26(2), 320-341.

Silva, M. P. T., \& Ambrósio, J. A. C. (2002). Kinematic data consistency in the inverse dynamic analysis of biomechanical systems. Multibody System Dynamics, 8(2), 219-239.

Smidt, G. L. (1973). Biomechanical analysis of knee flexion and extension. J Biomech, 6(1), 79-92.

Stansfield, B. W., Nicol, A. C., Paul, J. P., Kelly, I. G., Graichen, F., \& Bergmann, G. (2003). Direct comparison of calculated hip joint contact forces with those measured using instrumented implants. An evaluation of a three-dimensional mathematical model of the lower limb. J Biomech, 36(7), 929-936.

Steele, K. M., Demers, M. S., Schwartz, M. H., \& Delp, S. L. (2012). Compressive tibiofemoral force during crouch gait. Gait Posture, 35(4), 556-560. 
Taddei, F., Martelli, S., Valente, G., Leardini, A., Benedetti, M. G., Manfrini, M., \& Viceconti, M. (2012). Femoral loads during gait in a patient with massive skeletal reconstruction. Clin Biomech (Bristol, Avon), 27(3), 273-280.

Winby, C. R., Lloyd, D. G., \& Kirk, T. B. (2008). Evaluation of different analytical methods for subject-specific scaling of musculotendon parameters. J Biomech, 41(8), 1682-1688.

Winter, S. L., \& Challis, J. H. (2010). The expression of the skeletal muscle force-length relationship in vivo: a simulation study. J Theor Biol, 262(4), 634-643.

Xiao, M., \& Higginson, J. (2010). Sensitivity of estimated muscle force in forward simulation of normal walking. J Appl Biomech, 26(2), 142-149.

Xiao, M., \& Higginson, J. S. (2008). Muscle function may depend on model selection in forward simulation of normal walking. J Biomech, 41(15), 3236-3242.

Zajac, F. E. (1989). Muscle and tendon: properties, models, scaling, and application to biomechanics and motor control. Crit Rev Biomed Eng, 17(4), 359-411.

14

15 
1 Figures captions

2 7 8 9

Figure 1: Flowchart of the three musculo-skeletal models used to generate motion (i.e., kinematic parameters $q_{k}, \dot{q}_{k}, \ddot{q}_{k}$ ) from the command of the task (i.e., muscle excitation $u_{j}$ ). Both kinematic parameters $q_{k}, \dot{q}_{k}, \ddot{q}_{k}$ and joint reactions (i.e., $g_{l}, \lambda_{l}$ or $K_{l} \Phi_{l}$ ) are deduced from the musculo-tendon forces $f_{j}$.

Figure 2: Flowchart of the inverse dynamics-based static optimization prediction method minimizing the weigthed sum of musculo-tendon forces $f_{j}$ squared.

Figure 3: Flowchart of a variant of the inverse dynamics-based static optimization prediction method minimizing the sum of muscle activations $a_{j}$ squared.

Figure 4: Flowchart of the EMG-to-force prediction method.

Figure 5: Flowchart of the forward dynamics assisted data tracking prediction method.

Figure 6: Personalization of the musculo-skeletal models parameters

a) Active force-length, force-velocity and passive force-length curves $f_{j}^{M_{a}}, f_{j}^{M_{v}}, f_{j}^{M_{p}}$ (personalized using calibration procedures)

b) Muscle 3D geometry, e.g., $\mathbf{u}_{j}^{f}$ (personalized through medical imaging)

c) Kinematic constraints $\Phi_{l}$ (not personalized)

d) Bone and ligament 3D geometry, e.g., $\mathbf{u}_{l}^{g}$ (personalized through medical imaging) and force-strain ligament curves (not personalized) 


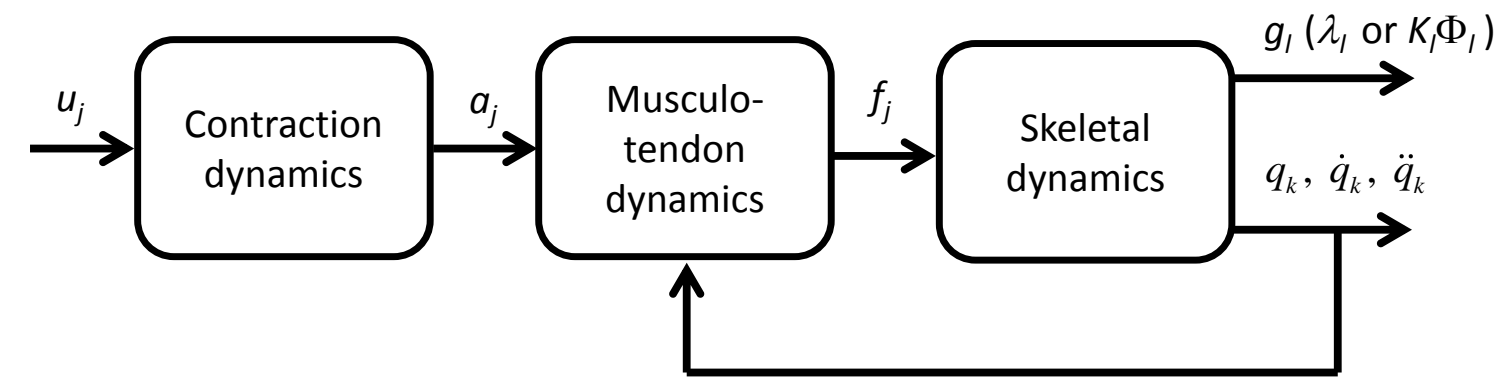

Figure 1 


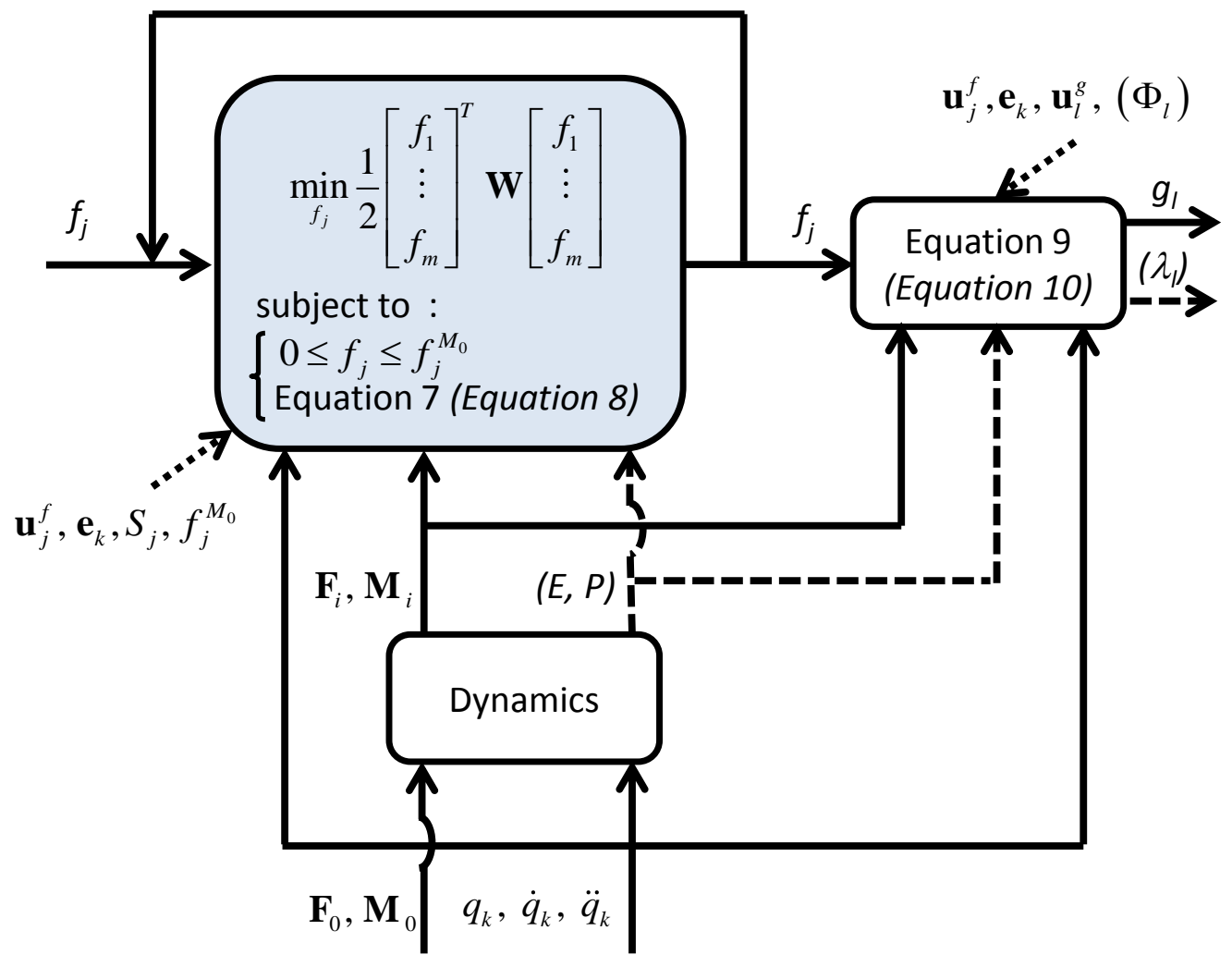

Figure 2 


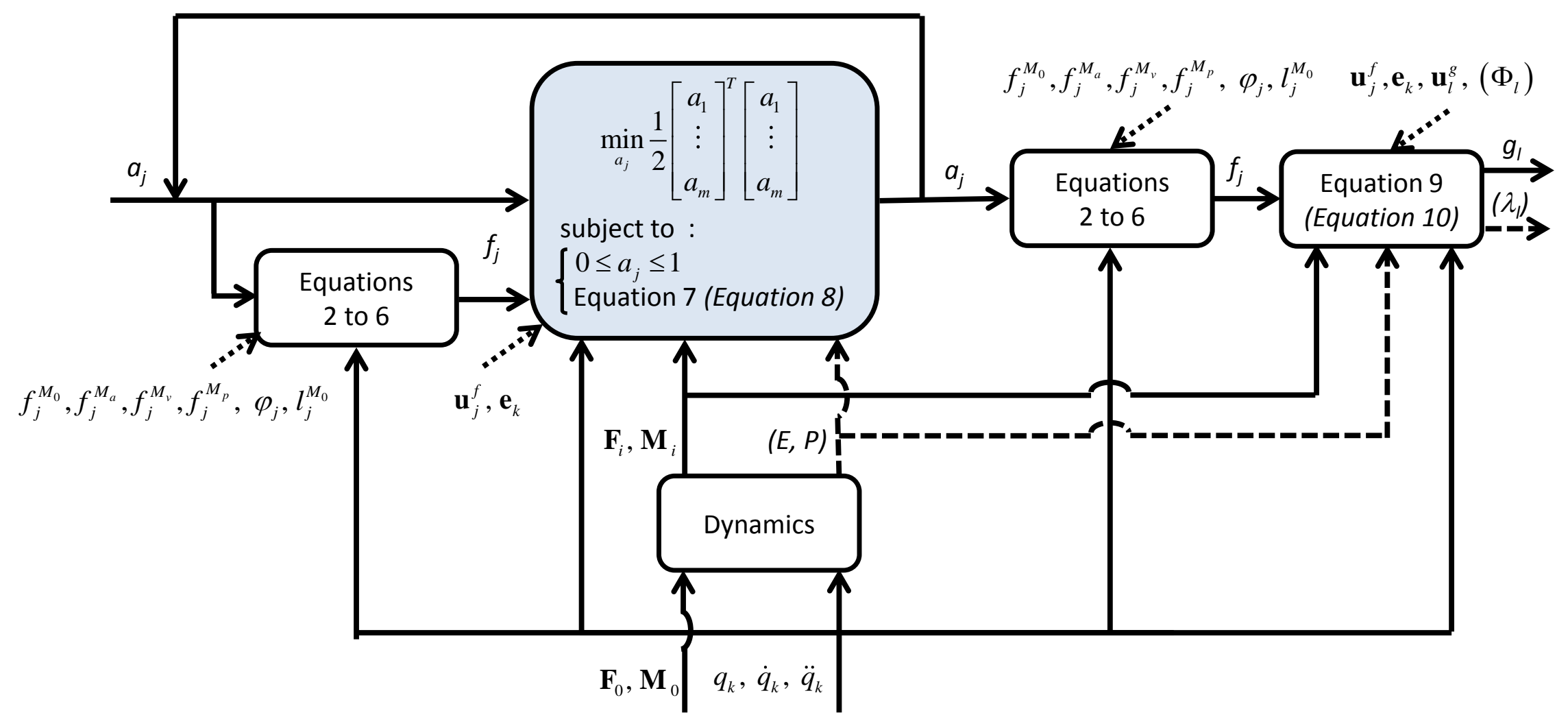

Figure 3 


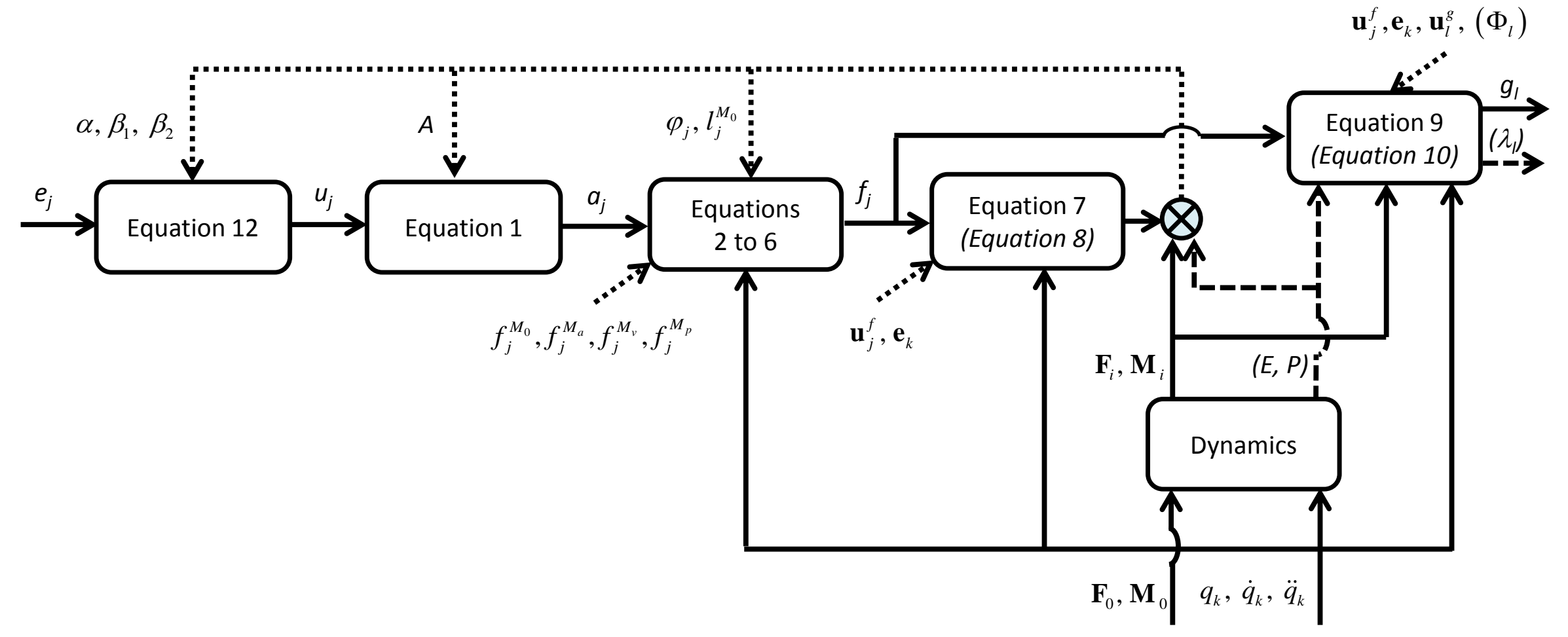

Figure 4 


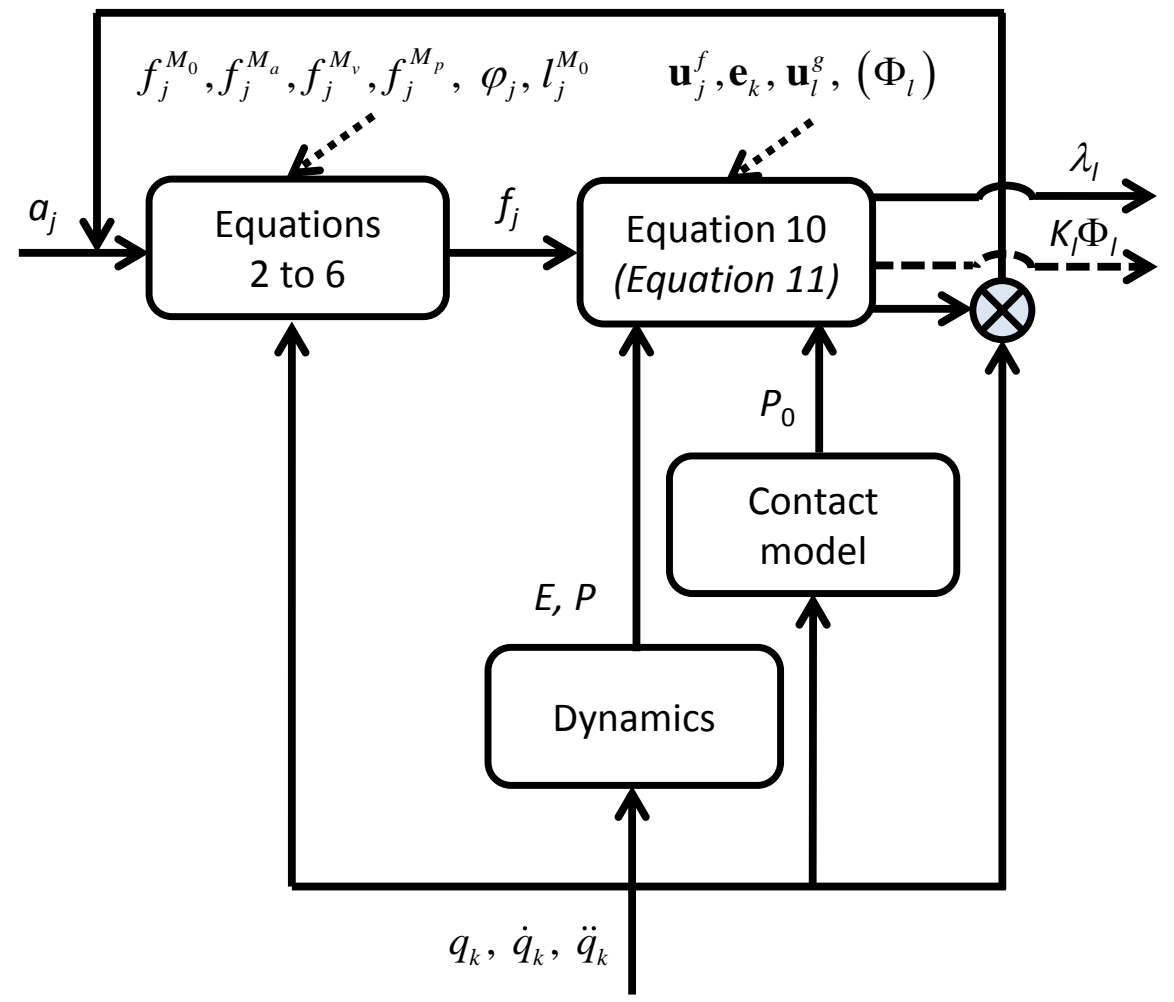

Figure 5 


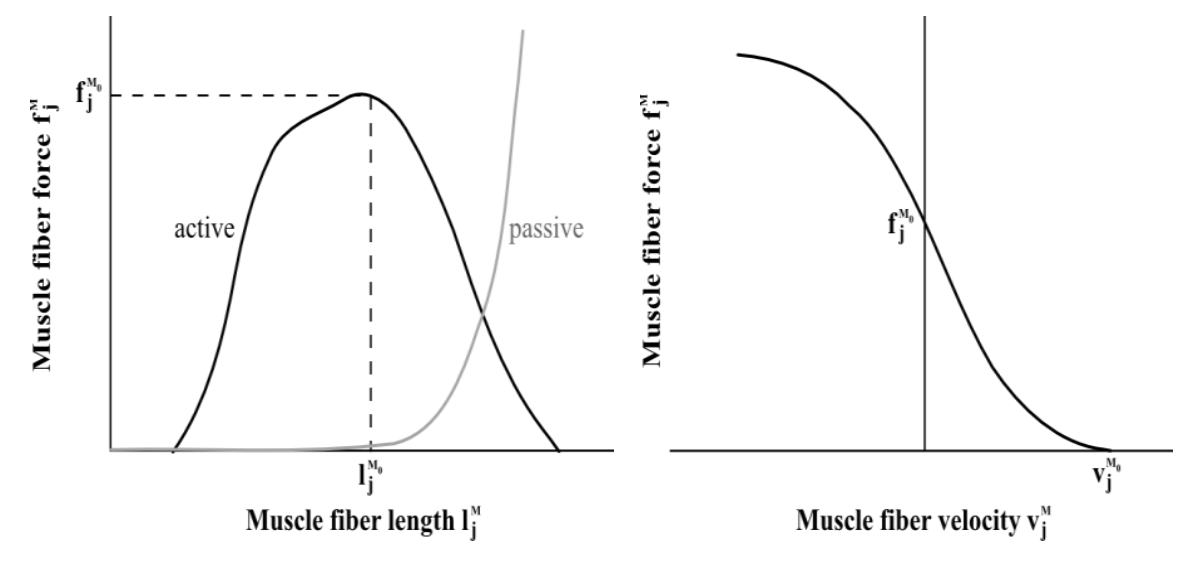

a

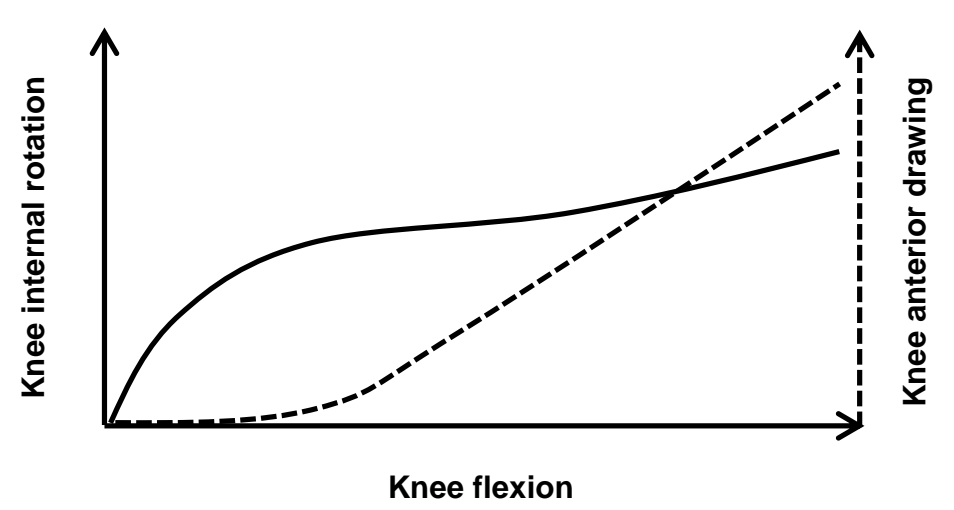

C

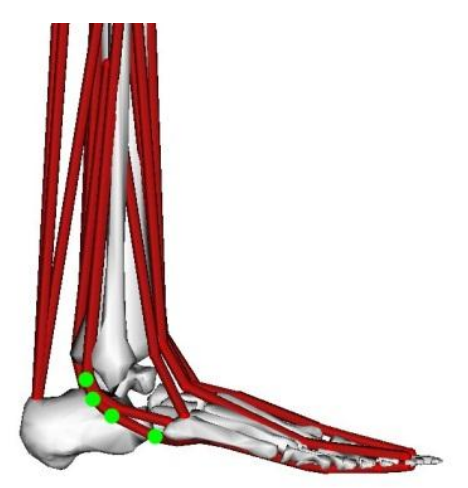

b

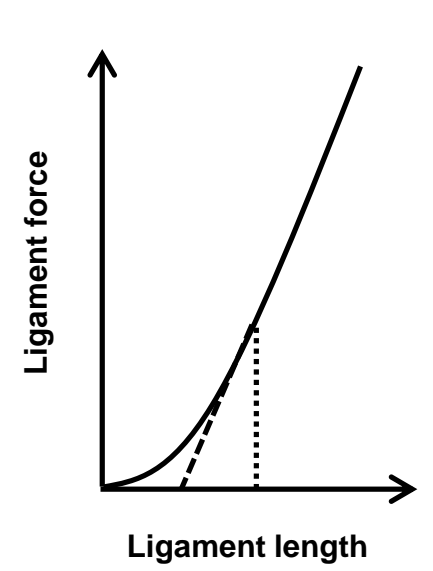

d

Figure 6 